\title{
Cuprous Oxide Layers Grown on Copper. Effect of CO Adsorption
}

\author{
L.M. Gassa, ${ }^{a}$ A.M. Castro Luna, ${ }^{a}$ R.M. Torres Sánchez, ${ }^{b}$ J.O. Zerbino ${ }^{\mathrm{a}, *}$ \\ ${ }^{a}$ Instituto de Investigaciones Fisicoquimicas Teóricas y Aplicadas (INIFTA), UNLP, Sucursal \\ 4, C.C. 16, (1900) La Plata, Argentina. \\ ${ }^{b}$ Centro de Tecnología de R. Minerales y Cerámica. C.C. 49, (1987) M. B. Gonnet, Argentina.
}

Received 31 December 2002; accepted in revised form 26 May 2003

\begin{abstract}
The semiconducting properties of anodic passive films formed on polycrystalline copper in aqueous borax solutions, $\mathrm{pH}$ 9.2, are studied using electrochemical impedance spectroscopy (EIS) and voltammetry. The semiconducting nature of the cuprous passive layer is analysed in the potential region near de rest potential as a function of the electrode potential and the presence of $\mathrm{CO}$ dissolved in the electrolyte. The oxide formation is explained as a sequence of $\mathrm{Cu}_{2} \mathrm{O}$ growth, cation adsorption, $\mathrm{Cu}$ (II), and dissolution steps similarly to previous reported investigations for the metal in $\mathrm{CO}$ free solutions. The different growth conditions change the defect or excess of cations accumulated in the outer side of the cuprous layer/electrolyte interface leading to different semiconducting properties.
\end{abstract}

Keywords: copper oxide, carbon monoxide, EIS, isoelectric point, semiconducting properties.

\section{Introduction}

The interface copper/CO plays a critical role in catalysis and corrosion. Copper electrodes show catalytic effects for $\mathrm{CO}_{2}$ reduction with formation of adsorbed $\mathrm{CO}$ as reaction intermediate and the selective production of methane, ethylene and alcohols [1-3]. CO adsorption causes at cathodic potentials a partial passivation decreasing the $\mathrm{H}_{2}$ evolution current [1]. Various theoretical adsorbate/substrate interaction models are developing that include both $\mathrm{CO} / \mathrm{CO}$ and $\mathrm{CO} /$ substrate coupling phenomena [4-7].

\footnotetext{
* Corresponding author. E-mail address: jzerbino@inifta.unlp.edu.ar
} 
Recently published articles [8-9] investigate the passive films formed on copper in borax at $\mathrm{pH} 9.2$ for cathodic potentials to that corresponding to the bulk formation of $\mathrm{CuO}$. Variations in the $\mathrm{Cu}_{2} \mathrm{O}$ structure and film growth rate are observed in the case of the addition of millimolar concentrations of different ions in electrolytes $\left(\mathrm{SO}_{4}{ }^{-2}, \mathrm{CO}_{3}{ }^{-2}\right)$. The presence of either $\mathrm{Cu}(\mathrm{II})$ adsorbed on the $\mathrm{Cu}_{2} \mathrm{O} /$ electrolyte interface or the formation of a $\mathrm{CuO}_{0.67}$ phase is reported at cathodic potentials not far from the $\mathrm{Cu}_{2} \mathrm{O} / \mathrm{CuO}$ redox potential. In a last publication [10] the effect of $\mathrm{CO}$ on the formation of incipient copper oxide is investigated using ellipsometry and isoelectric point measurements.

In this paper electrochemical impedance spectroscopy (EIS) and voltammetry are used investigating the structure of the oxide layers formed under different growth conditions in saturated $\mathrm{CO}$ aqueous solutions.

\section{Experimental}

The experimental set-up has been described in previous works [8-9]. Polycrystalline copper rods $\left(99.99 \%\right.$ purity, area $\left.0.4 \mathrm{~cm}^{2}\right)$ were used as working electrodes. Prior to each experiment, the electrodes were mechanically polished to a mirror finish with fine grade alumina powder of 0.3 and $0.05 \mu \mathrm{m}$.

The experiments were performed at room temperature and in borate buffer solutions $\left(\mathrm{Na}_{2} \mathrm{~B}_{4} \mathrm{O}_{7} 0.05 \mathrm{M}\right)$ under either $\mathrm{N}_{2}$ bubbling or the same solution saturated with CO. All experiments were performed using calomel reference electrode (SCE).

Electrochemical impedance measurements were carried out using an Analyzer "Zahner IM6" Impedance Spectrum (Zahner Messtechnik GmbH \& Co KG, Kronach, Germany) [9] . Before each experiment, the polished electrode was cathodized at $E_{c}=-1.3 \mathrm{~V}$ during 1 minute and scan at $v=0.5 \mathrm{mV} / \mathrm{s}$ up to $E_{a}:-140$ $\mathrm{mV}<E_{a}<-60 \mathrm{mV}$. Then, it was pre-anodised at $E_{a}$ for $1 \mathrm{~h}$ to establish a quasisteady state corresponding to almost constant thickness and passive layer composition according to the fixed $E_{a}$ value. The impedance measurements in the $65 \mathrm{kHz} \leq f \leq 1 \mathrm{mHz}$ frequency range were started at this upper $E_{a}$ potential limit 
and proceeded in steps of $0.02 \mathrm{~V}$ towards lower E potentials within the passive region.

Isoelectric point (iep) determinations were performed by means of diffusion potential measurement and the transport number value was obtained in the same way as described elsewhere [11-14]. Copper powder (Arqimex, Wolstenholme) was used, mean particle diameter 8.5-10.5 micrometres, and $\mathrm{CuO}$ Merck analytical grade, surface area $14.6 \mathrm{~m}^{2} / \mathrm{g}$. Previous to each experiment the metal powder was washed with acetone/water solutions. The oxide particles were used without further treatment.

\section{Results and Discussion}

\section{Voltammetric Data}

Fig. 1 shows the current potential, $i$ vs. E, plot during the reduction of the spontaneously formed oxide layer and the hydrogen evolution. When fresh polished copper electrodes are immersed in aqueous solution the open circuit potential, $E_{o c}$, is about $-0.3 \mathrm{~V}$, and this value shifts anodically with the immersion time. After 5 min of immersion $E_{o c}$ is equal to $-0.16 \mathrm{~V}$ and $=-0.25 \mathrm{~V}$ in solution free from $\mathrm{CO}$ and saturated with $\mathrm{CO}$, respectively (Fig. 1a). During the first cathodic scan the peaks Ia, Ib, Ic and II are observed. The second cycle obtained between $E_{c}=-1.3 \mathrm{~V}$ and $E_{a}=-0.48 \mathrm{~V}$ shows only one cathodic peak at $0.63 \mathrm{~V}$ (peak I), which corresponds to the reduction of the $\mathrm{Cu}_{2} \mathrm{O}$ layer formed during the first anodic scan. The I and II peak potentials depend on the preparation conditions and may be related to $\mathrm{Cu}_{2} \mathrm{O}$ clusters of different thickness and different cationic defect. Furthermore, at potentials lower than $-1.1 \mathrm{~V}$ it is reported that the $\mathrm{CO}$ adsorbed decreases the current corresponding to the $\mathrm{H}_{2}$ evolution. At more cathodic potentials the surface becomes free of adsorbed products [1]. 


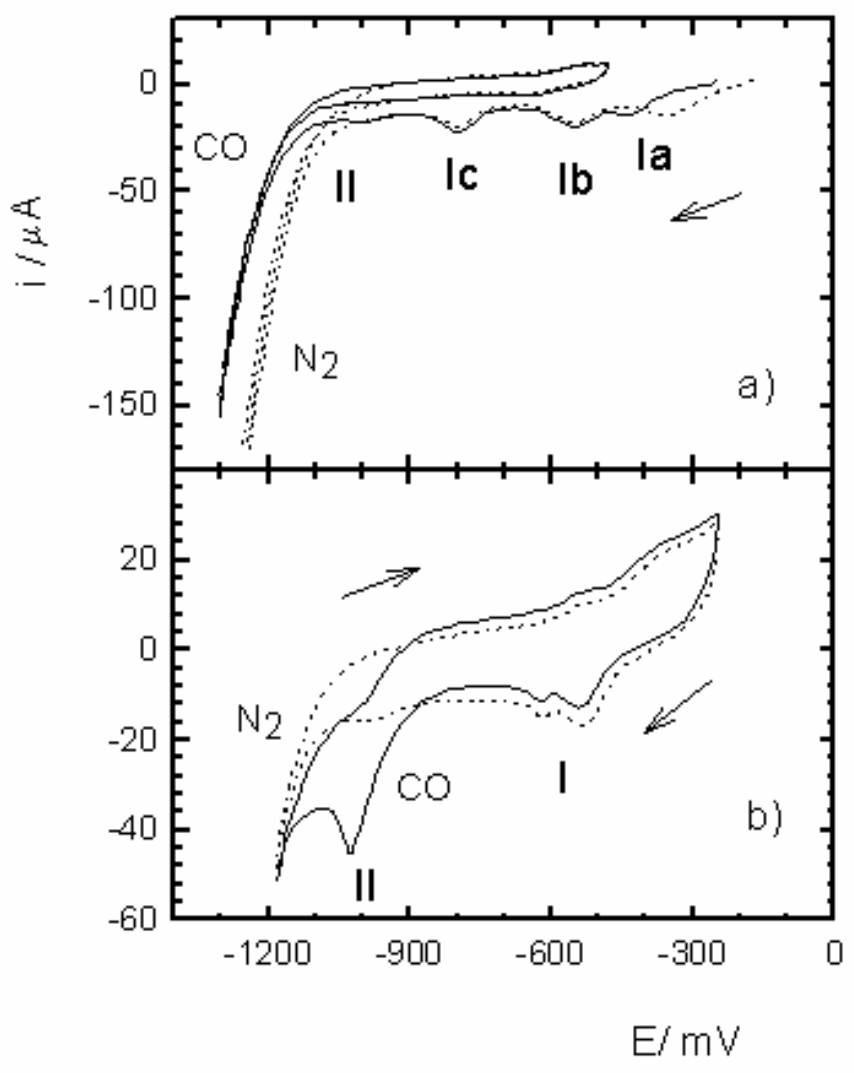

Figure 1. Current/potential plot corresponding to: a) First cathodic scan between the open circuit potential and the cathodic limit $E_{c}=-1.3 \mathrm{~V}$, followed by a potential cycle with anodic limit $E_{a}=-0.48 \mathrm{~V}$. b) Cyclic voltammogram recorded between $E_{c}=-1.2 \mathrm{~V}$ and $E_{a}=-0.25 \mathrm{~V}$. Dashed lines: CO free solutions, full lines: CO saturated solutions. Solution $\mathrm{pH}=9.2, v=0.5 \mathrm{mV} \mathrm{s}^{-1}$.

Electrochemical and optical studies show that the oxide is composed of $\mathrm{Cu}_{2} \mathrm{O}$ with a surface excess of $\mathrm{Cu}(\mathrm{II})$ ions. The oxide/electrolyte structure of a multilayer $\mathrm{Cu}_{2} \mathrm{O}$ film may be similar to the previously reported $\mathrm{CuO}_{0.67}$ layers $[9,15]$. The thickness of the different layers depends on the potential, time and stirring conditions.

In the presence of $\mathrm{CO}$ several experiments show a very high faradaic current contribution at $-1.0 \mathrm{~V}$ (Fig. 1b, Peak II) during the cathodic scan previous to the $\mathrm{H}_{2}$ evolution current. After bubbling $\mathrm{N}_{2}$ the dissolved $\mathrm{CO}$ is removed, peak II decreases and a very small peak is observed at $-0.98 \mathrm{~V}$ in the $\mathrm{CO}$ free solution. In previous articles this small peak was already reported and it may be attributed 
to oxide species formed on high active metal sites, like kink sites and step edges. These aging $\mathrm{Cu}_{2} \mathrm{O}$ species are more stable under cathodic polarization than that corresponding to the peaks observed at $-0.6 \mathrm{~V}$ (Peak I). The current intensity of peak Il in $\mathrm{CO}$ saturated solutions shows very high dispersion and in many experiments peak II is absent. However in all the experiments there is correspondence between the developed catalytic surface which shows the peak II in $\mathrm{CO}$ saturated solutions and the presence of the small peak observed at nearly the same potential in $\mathrm{CO}$ free solutions. This indicates $\mathrm{CO}$ adsorbed on the oxides monolayer patches formed on the recently polished and cathodized electrode that show high catalytic activity for the reduction of $\mathrm{CO}$ to methane and alcohols [1,16-18]. Peak Il charge in CO free solution corresponds to less than $5 \%$ of a monolayer. The adsorption of $\mathrm{CO}$ on copper may involve several phenomena as long range attractive interactions and coupling between the adsorbate and lattice phonons. Therefore, the formation of $\mathrm{CO} / \mathrm{Cu}_{2} \mathrm{O}$ clusters may explain the probable catalytic effect of these fractional oxide monolayers $[5,6,16]$.

\section{Isoelectric point measurements}

Through iep measurements is investigated the diffuse layer formed on both copper and copper oxide particles after immersion in $\mathrm{CO}$ saturated and $\mathrm{CO}$ free solutions. There are not changes observed in the $i_{p H}$ value $(\mathrm{pH} 10.8)$ for $\mathrm{CuO}$ particles dipped during 20 minutes in solutions in presence or in the absence of $\mathrm{CO}$. The similar iep measured on $\mathrm{Cu}$ in $\mathrm{CO}$ free solutions and $\mathrm{CuO}$ particles in solutions with and without $\mathrm{CO}$ indicates similar $\mathrm{OH}^{-} / \mathrm{O}^{2-}$ ratio for these diffuse layers.

On the other side, a significant decrease of around one $\mathrm{pH}$ unit is observed for $\mathrm{Cu}$ particles in solutions saturated with $\mathrm{CO}$ related to the $i e p_{p H}$ value obtained in free $\mathrm{CO}$ solutions. The adsorption of $\mathrm{CO}$ on the $\mathrm{Cu} / \mathrm{Cu}_{2} \mathrm{O}$ interface decreases the isoelectric point from 10.8 to 10.1 indicating lower surface cationic defect in the presence of CO $[10,19]$. 


\section{Electrochemical Impedance Spectroscopy Data}

The presence of either $\mathrm{CO}$ or millimolar concentration of $\mathrm{CO}_{3}{ }^{2-}$ and $\mathrm{SO}_{4}{ }^{2-}$ produces detectable changes in the oxide structure and the oxide growth kinetic when the oxide layer is formed using low sweep rate, $v=0.5 \mathrm{mV} \mathrm{s}^{-1}[9,20]$.

For the oxide grown after anodization at $E_{a},-140 \mathrm{mV}<E_{a}<60-\mathrm{mV}$ the impedance diagram exhibits slightly distorted capacitive semicircle at high frequencies followed by a not well defined second contribution. The time constant at high frequencies could be related to the $\mathrm{Cu}_{2} \mathrm{O}$ electronic properties.

The whole set of experimental data can be well described by the following transfer function:

$$
\mathrm{Z}(\mathrm{j} \omega)=\mathrm{R}_{\Omega}+1 /\left([\mathrm{CPE}]+\left(\mathrm{R}_{\mathrm{t}}+\mathrm{Z}_{\mathrm{w}}\right)^{-1}\right)
$$

where $\omega=2 \pi f, R_{\Omega}$ corresponds to the ohmic resistance of the electrolyte, [CPE] is the constant phase element given by $[\mathrm{CPE}]=\left[\mathrm{C}(\mathrm{j} \omega)^{\alpha}\right]^{-1}, C$ is the high frequency capacitance, $\alpha$ takes into account the distribution of time constants due to surface in-homogeneities, $R_{t}$ is the charge transfer resistance associated with the couple $\mathrm{Cu} / \mathrm{Cu}_{2} \mathrm{O}$ and $Z_{w}$ could be associated with a finite-length diffusion process.

The analysis of the impedance parameters associated with the lowest frequencies denotes a complex process [21]. More work is in progress to correlate the low frequency response and the time constants involved [20-23]. The measured capacitance values associated with the high frequencies, $\mathrm{C} \approx 18$ and $10 \mu \mathrm{F} \mathrm{cm}$ and $\alpha \approx 1$, are typical of a metal covered with a passive film [23] and may be considered as the passive film and double layer capacitance, $C_{H}$, connected in series. The capacitances have lower values than the typical $C_{H}$ and are associated to the space-charge capacitance of a semiconducting film, $C_{S C}$ [9]. The potential dependence of $C_{S C}$ should obtain the Mott-Schottky relation:

$$
\mathrm{C}_{\mathrm{SC}}{ }^{-2}=\left(2 / \mathrm{e} \mathrm{N} \mathrm{Nc}_{\mathrm{sc}} \varepsilon \varepsilon_{0}\right)\left[\left(-\mathrm{E}+\mathrm{E}_{\mathrm{FB}}-(\mathrm{kT} / \mathrm{e})\right]\right.
$$

where $N_{S C}$ and $E_{F B}$ are the carrier concentration and the flat band potential of the oxide, respectively. The other symbols have the usual meanings. 
Similar to previous studies, the resulting Mott-Schottky plots show two relatively well defined linear regions with both positive and negative slopes corresponding to the $\mathrm{Cu} / \mathrm{Cu}_{2} \mathrm{O}$ and the $\mathrm{Cu} / \mathrm{CuO}$ flat band $(F B)$ potential domains, $-0.41 \mathrm{~V}$ and $0.05 \mathrm{~V}$ respectively (Fig. 2). The $\alpha$ vs. $E$ dependencies are $0.78<\alpha<0.84$, $0.798<\alpha<0.82$, and $0.68<\alpha<0.74$ for $E_{a}=-60 \mathrm{mV},-100 \mathrm{mV}$, and $-140 \mathrm{mV}$ respectively. The fitted $\alpha$ are practically independent on the presence of $\mathrm{CO}$. The $\alpha$ variation indicates a progressive compactness of the $\mathrm{Cu}_{2} \mathrm{O}$ layer in the region dominated by the $\mathrm{Cu} / \mathrm{CuO} F B$ potential and a decrease in compactness in the $\mathrm{Cu}_{2} \mathrm{O} / \mathrm{Cu} F B$ potential region. The change is related to a first small decrease followed by an increase of either inter-grain or surface cation defect domains in the growing $\mathrm{Cu}_{2} \mathrm{O}$ layer.

The oxidation of $\mathrm{Cu}$ to $\mathrm{Cu}_{2} \mathrm{O}$ proceeds by a hole mechanism and an accumulation of holes in $\mathrm{Cu}_{2} \mathrm{O}$ is required for the oxidation process and likewise depletion conditions are necessary for its reduction. For potentials $E_{a}$, anodic to the $\mathrm{Cu} / \mathrm{CuO}$ couple, $\left(E_{f b}\right)_{2} \cong-50 \mathrm{mV}$, a limit thickness is observed [8,9]. For $E_{a}<-50$ $\mathrm{mV}$ enough electrons are available to reduce the adsorbed $\mathrm{Cu}(\mathrm{II})$ to $\mathrm{Cu}(\mathrm{I})$, and the film thickness increases for increasing $\mathrm{E}$. The results indicate that the $\mathrm{Cu}_{2} \mathrm{O}$ growth depends on the electric potentials developed both at the metal/oxide, $E_{M O}$, and at the $\mathrm{Cu}_{2} \mathrm{O} /$ electrolyte interface, $E_{O E}$. The $E_{O E}$ depends on the hydrate complexes formed on the $\mathrm{Cu}_{2} \mathrm{O}$ /electrolyte boundary and the presence of adsorbed CO.

The rest potential, $E_{o c}$, in the presence of $\mathrm{CO}$ shifts cathodically about 50 or 100 $\mathrm{mV}$ with respect to the $E_{o c}$ in $\mathrm{CO}$ free solutions. This shift indicates a decrease of the cationic defect with respect to that corresponding to free $\mathrm{CO}$ solution. For potentials lower than $-60 \mathrm{mV}$, decreasing polarization potential $E_{a}$ decreases the $E_{M O}$ value and the film thickness decreases [9].

For $E_{a}=-60 \mathrm{mV}$ (Fig. 2a), the Mott-Schottky plots show data practically independent on the presence of $\mathrm{CO}$ for the relatively thicker formed $\mathrm{Cu}_{2} \mathrm{O}$ films $(d \cong 30 \mathrm{~nm})[10]$. 


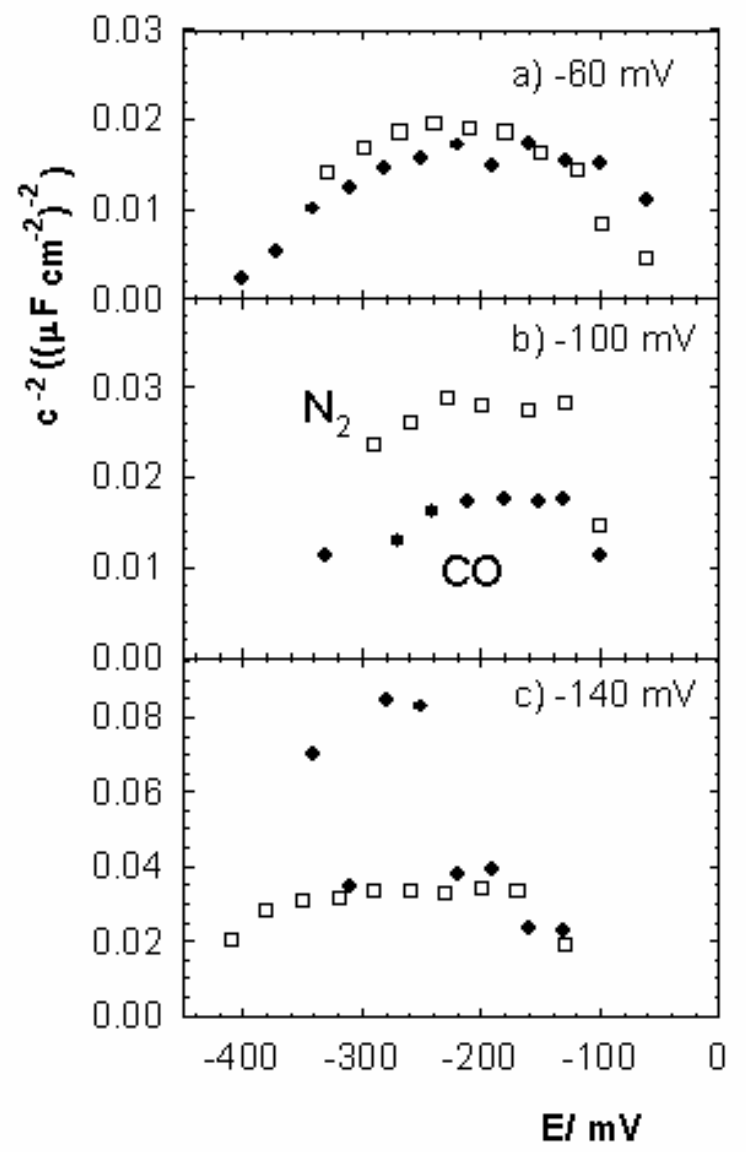

Figure 2. Mott-Schottky plots, $C_{S C}{ }^{-2}$ vs. $E$, of the oxide formed at $\mathrm{pH} 9.2$ using different $E_{a}$. a) $E_{a=}-60 \mathrm{mV}$, b) $E_{a=}-100 \mathrm{mV}$, c) $E_{a=}-140 \mathrm{mV}$. (•) CO saturate solution and $(\square) \mathrm{N}_{2}$ saturated solution.

For $E_{a}=-100 \mathrm{mV}$ (Fig. 2b), the films result more isolating in the presence of $\mathrm{CO}$ and this effect is related to the formation of thicker films in $\mathrm{CO}$ solution $(d \cong 40$ $\mathrm{nm})$ related to $\mathrm{CO}$ free solution [8-10,21]. The higher thickness is related to a decrease of the cationic defect. The $E_{O E}$ variation allows that more electrons are available to reduce the interfacial $\mathrm{Cu}(\mathrm{II})$ to $\mathrm{Cu}(\mathrm{I})$ and therefore the thickness increases.

For $E_{a}=-140 \mathrm{mV}$ (Fig. $\left.2 \mathrm{c}\right)$, the films are thinner $(d \cong 25 \mathrm{~nm})$ and the MottSchottky plot shows higher slops in the presence of CO. These films have high conductivity, which is related to $\mathrm{CO}$ adsorbed on $\mathrm{Cu}_{2} \mathrm{O}$ clusters. The adsorption of CO (a weak base) occurs on strong Lewis acid, highly co-ordinated, metal sites [24]. Besides chemisorbed oxygen coordinated with $\mathrm{Cu}(0)$ and $\mathrm{Cu}(\mathrm{I})$ may 
stabilize a $\mathrm{CO}$ cluster [25], while $\mathrm{Cu}$ (II) with co-ordination number six seems unstable relative to the $\mathrm{CO}$ adsorbed on oxides in which copper ions are found in square planar oxygen coordination [26].

The present results indicate that low coverage $\mathrm{Cu}(0)$ and $\mathrm{Cu}(\mathrm{I})$ species, coordinated with $\mathrm{CO}$, may promote with anodic polarization an initial increase in the rate growth of the $\mathrm{Cu}_{2} \mathrm{O}$ multilayer. On the other side, $\mathrm{CO}$ adsorption may stabilize cathodically polarized $\mathrm{Cu}(\mathrm{I})$ oxide patches showing catalytic effects in the $\mathrm{CO}$ and $\mathrm{CO}_{2}$ reduction process.

\section{Conclusion}

The adsorption of $\mathrm{CO}$ on the $\mathrm{Cu} / \mathrm{Cu}_{2} \mathrm{O}$ interface decreases the isoelectric point from 10.8 to 10.1 and the surface cationic defect in the $\mathrm{Cu}_{2} \mathrm{O} /$ electrolyte interface. The $\mathrm{CO}$ adsorbed on $\mathrm{Cu}_{2} \mathrm{O}$ increases the oxide growth rate for $E>-0.1$ $\mathrm{V}$. For more cathodic potentials, $E<-0.1 \mathrm{~V}$, the oxide multilayer grown in $\mathrm{CO}$ aqueous solutions shows higher conductivity and higher number of carriers than the $\mathrm{CO}$ free oxide. The catalytic reduction of $\mathrm{CO}$ on cathodically polarized copper electrodes may involve adsorbed CO on oxide monolayer cluster sites.

\section{Acknowledgements}

This research project was financially supported by the "Comisión de Investigaciones Científicas de la Provincia de Buenos Aires", CIC, the "Consejo Nacional de Investigaciones Científicas y Técnicas", CONICET, the "Universidad Nacional de La Plata", and the "Fundación Antorchas". Part of the equipment used in the experimental work was provided by DAAD. J.O.Z and A.M.CL. are members of the Research Career of CIC. The authors thank the Organising Committee of SIBAE XV (Évora, Portugal, 8-13 September 2002) for the helpful discussions.

\section{References}

1. H.J. Cardona, C. del Moral, C.R. Cabrera, J. Electroanal. Chem. 513 (2001) 45.

2. O. Koga, T. Matsuo, N. Hoshi, Y. Hori, Electrochim. Acta 44 (1998) 903.

3. Y. Hori, A. Murata, T. Tsukamoto, H. Wakebe, O. Koga, H. Yamazaki, Electrochim. Acta 39 (1994) 2495. 
4. M.W. Severson, A. Russell, D. Campbell, J.W. Russell, Langmuir 3 (1987) 2002.

5. S. Vollmer, G. Witte, Ch. Wöll, Catal. Letters 77 (2001) 97.

6. $\quad$ S.P. Lewis, A.M. Rappe, J. Chem. Phys. 110 (1999) 4619.

7. A.P. Graham, F. Hofmann, J.P. Toennies, J. Chem. Phys. 105 (1996) 2093.

8. J.O. Zerbino, M.F.L. Mele, J. Appl. Electrochem. 27 (1997) 335; 27 (1997).

9. J.O. Zerbino, L. Gassa, J. Solid. State Electrochem. 7 (2003) 177.

10. R.M. Torres Sánchez, A.M. CastroLuna, J.O. Zerbino, J. Colloid Interface Sci. (in press)

11. R.M. Torres Sánchez, H.J. Gasalla, E.E. Pereira, React. of Solids 7 (1989) 53.

12. R.M. Torres Sánchez, J. Mater. Sci. Letters 15 (1996) 461.

13. M. Tschapek, R.M. Torres, C. Wasowski, Z. Pflanzenernähr. Bodenk. 152 (1989) 73.

14. M. Tschapek, I. Natale, Kolloid S. für Polymers 251 (1973) 490.

15. H. Wieder, A.W. Czanderna, J. Appl. Phys. 37 (1966) 184.

16. G.G. Jernigan, G.A. Somorjai, J. Catal. 147 (1994) 567.

17. G. Kyriacou, A. Anagnostopoulos, J. Electroanal. Chem. 328 (1992) 233.

18. M. Janik-Czachor, A. Szummer, A. Molnar, M. Dolata, A. Kudelski, M. Varga, J. Bukoeska, K. Sikorski, Electrochim. Acta 45 (2000) 3295.

19. N. Kallay, Z. Torbic, E. Barouch, J. Jednacak-Biscan, J. Colloid Interface Sci. 118 (1987) 431.

20. J.O. Zerbino, C. Tapia, R.O. Lezna, Electrochem Approach to Selected Corr. Studies. IOM Communications. 28 Cap. 17 (2000) 225.

21. M. Metikos-Hukpvic, R. Babic, A. Marinovic, J. Electrochem. Soc. 145 (1998) 4045.

22. M. Bojinov, J. Hilden, T. Laitinen, K. Mäkelä, J. Piipo, T. Saario and J. Hinttala, in Passivity of Metals and Semiconductors, M.B. Ives, J.L. Luo and J. Rodda, Eds., The Electrochemical Society, Pennington, NJ (2000) pp. 555-560. 
23. A.M.P. Simões, M.G.S. Ferreira, B. Randot, M. da Cunha Belo, J. Electrochem. Soc. 137 (1990) 82.

24. H.M. Ismail, D.A. Cadenhead, I.M. Zaki, J. Colloid Interface Sci. 194 (1997) 482.

25. H.Y. Kwak, S.D. Oh, J. Colloid Interface Sci. 198 (1998) 113.

26. G.A. Parks, Chem. Rev. 65 (1965) 177. 